Science

February 2021, Volume 371 Issue 6531 Pages 835-838

https://doi.org/10.1126/science.abd3369

https://archimer.ifremer.fr/doc/00683/79474/

\title{
Human impacts on global freshwater fish biodiversity
}

Su Guohuan ${ }^{1, ~}{ }^{*}$, Logez Maxime ${ }^{2,3}$, Xu Jun ${ }^{4,5}$, Tao Shengli ${ }^{1}$, Villéger Sébastien ${ }^{6}$, Brosse Sébastien ${ }^{1}$

${ }^{1}$ Laboratoire Evolution et Diversité Biologique (EDB), UMR5174, Université Toulouse 3 Paul Sabatier, CNRS, IRD, Toulouse, France.

2 INRAE, Aix Marseille Univ, RECOVER, Aix-en-Provence, France.

3 Pôle R\&D "ECLA," Aix-en-Provence, France.

4 Donghu Experimental Station of Lake Ecosystems, State Key Laboratory of Freshwater Ecology and Biotechnology of China, Institute of Hydrobiology, Chinese Academy of Sciences, Wuhan, P.R. China.

${ }^{5}$ Laboratory for Marine Fisheries Science and Food Production Processes, Qingdao National

Laboratory for Marine Science and Technology, Qingdao, P.R. China.

${ }^{6}$ MARBEC, Univ Montpellier, CNRS, Ifremer, IRD, Montpellier, France.

*Corresponding author : Guohuan Su, email address : quohuan.su@gmail.com

\begin{abstract}
:
Freshwater fish represent one-fourth of the world's vertebrates and provide irreplaceable goods and services but are increasingly affected by human activities. A new index, Cumulative Change in Biodiversity Facets, revealed marked changes in biodiversity in $>50 \%$ of the world's rivers covering $>40 \%$ of the world's continental surface and $>37 \%$ of the world's river length, whereas $<14 \%$ of the world's surface and river length remain least impacted. Present-day rivers are more similar to each other and have more fish species with more diverse morphologies and longer evolutionary legacies. In temperate rivers, where the impact has been greatest, biodiversity changes were primarily due to river fragmentation and introduction of non-native species.
\end{abstract}


27 Rivers and lakes cover less than $1 \%$ of the Earth's surface but they host large levels of

28 biodiversity, including near 18,000 fish species that represent one quarter of global vertebrates

29 (1-3). These freshwater fishes support the functioning and stability of ecosystems through their

30 contribution to biomass production and regulation of trophic networks and nutrient cycles (4).

31 Freshwater fishes also contribute to human welfare as key food resources (5), and for recreative 32 and cultural activities $(2,6)$.

33 For centuries human populations have directly affected fish biodiversity (7) through extraction 34 and introduction of non-native species $(8,9)$. Human activities have also modified the natural environment by changing land uses, altering flow regimes, fragmenting rivers by dams, polluting soil and waters and altering climate, actions that indirectly favor extinction of native species and/or establishment of non-native species (10-13). Consequently, these direct and indirect anthropogenic impacts have led to modification of local species compositions $(8,9)$. However, biodiversity is not restricted to purely taxonomic components but also includes functional and phylogenetic diversities. These two latter facets determine how organisms affect ecosystem functioning and stability (14-18) and are thus essential for conservation.

Here, we assess the extent to which six key facets of freshwater fish biodiversity (taxonomic, functional and phylogenetic richness and corresponding dissimilarities between river basins) have changed over the last two centuries in 2,456 river basins, covering almost the entire continental surface of the Earth (excluding deserts and poles) and hosting $>14,000$ species (> 
$80 \%$ of the global freshwater fish pool) (19). We computed an index of cumulative change in biodiversity facets (CCBF) which ranges from 0 to 12 with higher scores depicting stronger changes across more biodiversity facets. A score higher than 6 indicates either changes in all the six facets, or changes higher than median in more than three biodiversity facets (Fig. 1) (20). We further unravel the natural and anthropogenic drivers that have led to the observed changes across the main regions of the world.

More than half of the river basins $(52.8 \%, 1,297$ rivers covering $40.2 \%$ of the world continental surface and $37.3 \%$ of the world river length) show CCBF scores higher than 6 (Fig. 2), revealing deep and spatially distributed anthropogenic impacts on fish biodiversity. In contrast, one third of the river basins $(35.7 \%, 878$ rivers) did not experience changes in local richness but only changes in dissimilarity with assemblages from the same realm (Fig. S1). Those least impacted river basins are mostly small-sized and occupy only $13.4 \%$ of the world river basin surface and support 3,876 species, only $21.7 \%$ of the world fish fauna. Moreover, the least impacted rivers are overrepresented in Afrotropical and Australian regions, whereas the Neotropics, although being the richest in species, functional and phylogenetic diversity $(21,22)$ account for less than $6 \%$ of the "least impacted" category (Fig. S1).

Fish assemblages from the temperate regions of Nearctic, Palearctic and Australian realms experienced the largest biodiversity changes, with more than $60 \%$ of the rivers reaching a CCBF score higher than 6 (Fig. 2 a,b). Overall biodiversity changes in temperate regions (CCBF $=8.6$ \pm 0.1 , mean \pm standard error) were higher than in tropical rivers $(\mathrm{CCBF}=5.1 \pm 0.1)$. For instance, large temperate rivers such as the Mississippi, Danube, or Murray-Darling show 
CCBF scores higher than 8, whereas large tropical rivers, such as the Amazon, Congo or Mekong were less impacted $(\mathrm{CCBF}=6$, Fig. $\mathrm{S} 2)$. Such a spatial pattern is consistent with previous studies on changes in taxonomic richness and dissimilarity of freshwater fishes $(8,9)$, and with historical reports on anthropogenic degradation of ecosystems (23), but contrasts with changes observed in other taxa for which changes in biodiversity were the highest in tropical regions [e.g., for marine biome (24), forest (25)].

Mapping the patterns of changes across the six diversity components revealed discrepancies between richness facets (Fig. 3). Except for a few rivers in the northern part of the Palearctic and Nearctic realms, fish biodiversity did not decline in most of the rivers (Fig. 3 a,b,c). This markedly differs from recent results documenting the decline in freshwater living resources at the local scale (i.e. over 1-10 km of river stretch) within some of these river basins $(12,26)$. Interestingly, we report an inverse trend in freshwater fish for local taxonomic, functional and phylogenetic richness in more than half of the world rivers (Fig. 3 a,b,c, Fig. 4). This increase in local diversity is primarily explained by anthropogenic species introductions that compensate for or even exceed extinctions in most rivers (27). 170 fish species went extinct in a river basin but this number might be underestimated due to time lag between effective extinction and published extinction reports (28). In addition, $23 \%$ of freshwater fish species are currently considered as threatened (29), which might turn to increase extinctions in the near future (26).

In addition to the overall increase in richness of fish assemblages in river basins, a general declining trend in biological dissimilarity between river basins, that is biotic homogenization, appears pervasive throughout the world's rivers (Fig. 3 d,e,f). Functional dissimilarity was the 
most impacted facet with a decrease in $84.6 \%$ of the rivers while taxonomic dissimilarity and phylogenic dissimilarity decreased in only $58 \%$ and $35 \%$ of the rivers (Fig. 3 d,e,f). The discrepancy between change in functional diversity and changes in taxonomic and phylogenetic diversity (Fig. 4) primarily stems from the origin of non-native species introduced in rivers. Species translocated from a river to nearby basins promote losses of dissimilarity because they often already occur as natives in many rivers of the realm and are often functionally and phylogenetically close to other native species $(9,30)$. In contrast, exotic species (i.e. originating from other realms) are less frequently introduced and their divergent evolutionary history with native species led to increase phylogenetic dissimilarity of their recipient rivers (30). For instance, the exotic species introduced in only a few rivers of Europe (e.g., the mosquitofish, Gambusia affinis, established in south-western Europe or the brook trout, Salvelinus fontinalis, established in cold-water ecosystems) (30), markedly enhanced the phylogenetic dissimilarity between those rivers. However, exotic species even from distinct evolutionary lineages could share functional traits with some native species, hence leading to increase phylogenetic dissimilarity but decrease functional dissimilarity (Fig. 3). For instance, European trout, Salmo trutta and Pacific Salmon, Oncorhynchus mykiss, belong to an order (Salmoniformes) absent from the Australian realm but those exotic salmonids are functionally similar to some native Australian fishes such as the spotted mountain trout, Galaxias truttaceus (Osmeriformes) (31).

The CCBF score was positively linked to human activities related to the industrialization and economic development, such as human footprint [FPT, (23)], with an increase of biodiversity changes with the FPT in all the industrialized and populated realms. River fragmentation by dams, represented by the degree of fragmentation index [DOF, (32)], was also a widespread 
disturbance in the Nearctic and Palearctic realms (Fig. 2c) that experienced intensive damming for more than a century (33). Fragmentation by dams was also a significant driver of biodiversity change in the Neotropics, probably due to the rise of hydropower dam construction in this realm (34). Higher DOF values were reached in small or medium sized rivers, whereas the largest and most diverse rivers such as the Amazon, Orinoco or Congo remain mostly free flowing (32), but the current rise of dam construction on those rivers $(35,36)$ will constitute a major threat to their biodiversity. Apart from river fragmentation, consumptive water use for agriculture and industry [USE, (32)] was a significant driver of CCBF increase in the Nearctic realm, where water withdrawal for agriculture is intense $(32,37)$ and act in synergy with increasing DOF. In the Afrotropics, USE was the only significant human driver of CCBF, due to marked consumptive water use in regions with marked seasonal aridity $(32,37)$. In addition, the CCBF score was positively correlated to the richness in native species in most of the realms, indicating that the most speciose rivers are also the most impacted by biodiversity changes. Moreover, no negative associations between the species richness and the CCBF were observed, providing little support to the hypothesis of biotic resistance that assumes a higher resistance of species-rich assemblages against disturbances (38-40).

Conserving freshwater fish diversity in the least impacted rivers (accounting for $13.4 \%$ of the world basin surface) will remain under the target to protect at least $30 \%$ of the Earth's surface by 2030 , proposed by a broad coalition of environmental organizations $(41,42)$. This result suggests that reaching the freshwater fish target must involve consideration of not only the least impacted rivers, but also areas where biodiversity has already been eroded by human activities. Moreover, conservation has moved toward systematically identifying regions in need of 
132

protection (43). The discrepancy in biodiversity erosion we report between freshwater and marine and terrestrial ecosystems $(24,25)$ demonstrates that current measures of biodiversity erosion, derived from marine and terrestrial organisms, do not apply to freshwaters, and thus underlines the need to develop freshwater-focused conservation priorities. In addition, the mismatches between changes in taxonomic, functional and phylogenetic dissimilarities among the world freshwater fish fauna highlight the risk of evaluation based on change in a single facet as a surrogate of the changes in other facets. More importantly, our results highlight the need to consider the cumulative and synergistic effects of multiple human activities on the complementary facets of biodiversity. The CCBF index we propose presents a holistic measure of multiple measures of biodiversity change and offers potential for prioritizing and informing adaptive management and global conservation targets. Future studies and planning need to expand the focus from simple loss of species to integrated changes in facets of biodiversity resulting from interactions between synergetic human activities. 


\section{References and Notes:}

1. G. H. Allen, T. M. Pavelsky, Global extent of rivers and streams. Science 361, 585-588 (2018).

2. D. Dudgeon et al., Freshwater biodiversity: importance, threats, status and conservation challenges. Biological reviews 81, 163-182 (2006).

3. R. van der Laan, Freshwater fish list. (Almere, the Netherlands, ed. 30th, 2020).

4. S. Villéger, S. Brosse, M. Mouchet, D. Mouillot, M. J. Vanni, Functional ecology of fish: current approaches and future challenges. Aquatic Sciences 79, 783-801 (2017).

5. R. Hassan, R. Scholes, N. Ash, Ecosystems and human well-being: current state and trends. (Island Press, Washington, DC, 2005).

6. R. Arlinghaus et al., Opinion: Governing the recreational dimension of global fisheries. Proceedings of the National Academy of Sciences 116, 5209-5213 (2019).

7. R. C. Hoffmann, Economic development and aquatic ecosystems in medieval Europe. The American Historical Review 101, 631-669 (1996).

8. F. Leprieur, O. Beauchard, S. Blanchet, T. Oberdorff, S. Brosse, Fish invasions in the world's river systems: when natural processes are blurred by human activities. Plos Biology 6, e28 (2008).

9. S. Villéger, S. Blanchet, O. Beauchard, T. Oberdorff, S. Brosse, Homogenization patterns of the world's freshwater fish faunas. Proceedings of the National Academy of Sciences 108, 18003-18008 (2011).

10. H. M. Pereira et al., Scenarios for global biodiversity in the 21 st century. Science 330, 1496-1501 (2010). 
167 11. C. J. Vörösmarty et al., Global threats to human water security and river biodiversity. Nature 467, 555 (2010).

12. A. J. Reid et al., Emerging threats and persistent conservation challenges for freshwater biodiversity. Biological Reviews 94, 849-873 (2019).

13. D. Tickner et al., Bending the curve of global freshwater biodiversity loss: an emergency recovery plan. Bioscience 70, 330-342 (2020).

14. D. Mouillot, N. A. Graham, S. Villéger, N. W. Mason, D. R. Bellwood, A functional approach reveals community responses to disturbances. Trends in ecology \& evolution 28, 167-177 (2013).

15. S. Naeem, J. E. Duffy, E. Zavaleta, The functions of biological diversity in an age of extinction. Science 336, 1401-1406 (2012).

16. D. Craven et al., Multiple facets of biodiversity drive the diversity-stability relationship. Nature ecology \& evolution 2, 1579-1587 (2018).

17. P. Brun et al., The productivity-biodiversity relationship varies across diversity dimensions. Nature Communications 10, 5691 (2019).

18. C. Pimiento et al., Functional diversity of marine megafauna in the Anthropocene. Science Advances 6, eaay7650 (2020).

19. P. A. Tedesco et al., A global database on freshwater fish species occurrence in drainage basins. Scientific Data 4, 170141 (2017).

20. See supplementary materials.

21. A. Toussaint, N. Charpin, S. Brosse, S. Villéger, Global functional diversity of freshwater fish is concentrated in the Neotropics while functional vulnerability is 
widespread. Scientific reports 6, 22125 (2016).

22. D. L. Rabosky, Speciation rate and the diversity of fishes in freshwaters and the oceans. Journal of Biogeography 47, 1207- 1217 (2020).

23. O. Venter et al., Global terrestrial Human Footprint maps for 1993 and 2009. Scientific data 3, 160067 (2016).

24. S. A. Blowes et al., The geography of biodiversity change in marine and terrestrial assemblages. Science 366, 339-345 (2019).

25. M. C. Hansen et al., High-resolution global maps of 21st-century forest cover change. science 342, 850-853 (2013).

26. J. S. Albert et al., Scientists' warning to humanity on the freshwater biodiversity crisis. Ambio 50, 85-94 (2021).

27. A. Toussaint et al., Non - native species led to marked shifts in functional diversity of the world freshwater fish faunas. Ecology letters 21, 1649-1659 (2018).

28. S. T. Jackson, D. F. Sax, Balancing biodiversity in a changing environment: extinction debt, immigration credit and species turnover. Trends in ecology \& evolution 25, 153 160 (2010).

29. IUCN, The IUCN red list of threatened species Version 2017-3, http://www.iucnredlist.org., (2018).

30. S. Villéger, G. Grenouillet, S. Brosse, Functional homogenization exceeds taxonomic homogenization among European fish assemblages. Global Ecology and Biogeography 23, 1450-1460 (2014).

31. S. Burgin, Indirect consequences of recreational fishing in freshwater ecosystems: an 
exploration from an Australian perspective. Sustainability 9, 280 (2017).

32. G. Grill et al., Mapping the world's free-flowing rivers. Nature 569, 215 (2019).

33. B. Lehner et al., High - resolution mapping of the world's reservoirs and dams for sustainable river - flow management. Frontiers in Ecology and the Environment 9 , 494-502 (2011).

34. C. Zarfl, A. E. Lumsdon, J. Berlekamp, L. Tydecks, K. Tockner, A global boom in hydropower dam construction. Aquatic Sciences 77, 161-170 (2015).

35. E. P. Anderson et al., Fragmentation of Andes-to-Amazon connectivity by hydropower dams. Science advances 4, eaao1642 (2018).

36. K. O. Winemiller et al., Balancing hydropower and biodiversity in the Amazon, Congo, and Mekong. Science 351, 128-129 (2016).

37. P. Döll, K. Fiedler, J. Zhang, Global-scale analysis of river flow alterations due to water withdrawals and reservoirs. Hydrology and Earth System Sciences 13, 2413 (2009).

38. J. E. Duffy, J. S. Lefcheck, R. D. Stuart-Smith, S. A. Navarrete, G. J. Edgar, Biodiversity enhances reef fish biomass and resistance to climate change. Proceedings of the National Academy of Sciences 113, 6230-6235 (2016).

39. M. Loreau et al., Biodiversity and ecosystem functioning: current knowledge and future challenges. science 294, 804-808 (2001).

40. J. M. Levine, Species diversity and biological invasions: relating local process to

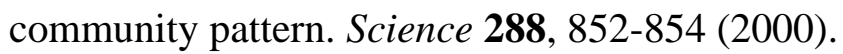

41. E. Dinerstein et al., A global deal for nature: guiding principles, milestones, and 
targets. Science advances 5, eaaw2869 (2019).

42. S. L. Pimm, C. N. Jenkins, B. V. Li, How to protect half of Earth to ensure it protects sufficient biodiversity. Science Advances 4, eaat2616 (2018).

43. C. R. Margules, R. L. Pressey, Systematic conservation planning. Nature 405, 243 (2000).

44. C. Lévêque, T. Oberdorff, D. Paugy, M. Stiassny, P. Tedesco, Global diversity of fish (Pisces) in freshwater. Hydrobiologia 595, 545-567 (2008).

45. S. Brosse et al., Fish-SPRICH: a database of freshwater fish species richness throughout the World. Hydrobiologia 700, 343-349 (2013).

46. H. Seebens et al., No saturation in the accumulation of alien species worldwide. Nature communications 8, 14435 (2017).

47. S. Blanchet et al., Non - native species disrupt the worldwide patterns of freshwater fish body size: implications for Bergmann's rule. Ecology Letters 13, 421-431 (2010).

48. G. Ceballos, P. R. Ehrlich, R. Dirzo, Biological annihilation via the ongoing sixth mass extinction signaled by vertebrate population losses and declines. Proceedings of the national academy of sciences 114, E6089-E6096 (2017).

49. M. S. Dias et al., Anthropogenic stressors and riverine fish extinctions. Ecological indicators 79, 37-46 (2017).

50. R. Froese, D. Pauly. (2018), vol. http://www.fishbase.org.

51. G. Su, S. Villéger, S. Brosse, Morphological diversity of freshwater fishes differs between realms, but morphologically extreme species are widespread. Global Ecology and Biogeography 28, 211-221 (2019). 
52. D. Bellwood, C. Goatley, S. Brandl, O. Bellwood, Fifty million years of herbivory on coral reefs: fossils, fish and functional innovations. Proceedings of the Royal Society B: Biological Sciences 281, 20133046 (2014).

53. S. Villéger, J. R. Miranda, D. F. Hernandez, D. Mouillot, Contrasting changes in taxonomic vs. functional diversity of tropical fish communities after habitat degradation. Ecological Applications 20, 1512-1522 (2010).

54. C. Penone et al., Imputation of missing data in life - history trait datasets: which approach performs the best? Methods in Ecology and Evolution 5, 961-970 (2014).

55. J. Bruggeman, J. Heringa, B. W. Brandt, PhyloPars: estimation of missing parameter values using phylogeny. Nucleic acids research 37, W179-W184 (2009).

56. D. L. Rabosky et al., An inverse latitudinal gradient in speciation rate for marine fishes. Nature 559, 392 (2018).

57. F. Leprieur et al., Partitioning global patterns of freshwater fish beta diversity reveals contrasting signatures of past climate changes. Ecology letters 14, 325-334 (2011).

58. D. J. Currie et al., Predictions and tests of climate - based hypotheses of broad - scale variation in taxonomic richness. Ecology letters 7, 1121-1134 (2004).

59. M. Dynesius, R. Jansson, Evolutionary consequences of changes in species' geographical distributions driven by Milankovitch climate oscillations. Proceedings of the National Academy of Sciences 97, 9115-9120 (2000).

60. J.-F. Guégan, S. Lek, T. Oberdorff, Energy availability and habitat heterogeneity predict global riverine fish diversity. Nature 391, 382-384 (1998).

61. W. Nordhaus, X. Chen, Global gridded geographically based economic data (G-econ), 
62. W. D. Nordhaus, Geography and macroeconomics: New data and new findings. Proceedings of the National Academy of Sciences 103, 3510-3517 (2006).

63. P. Döll, S. Siebert, Global modeling of irrigation water requirements. Water resources research 38, 8-1-8-10 (2002).

64. S. Villéger, N. W. H. Mason, D. Mouillot, New multidimensional functional diversity indices for a multifaceted framework in functional ecology. Ecology 89, 2290-2301 (2008).

65. D. P. Faith, Conservation evaluation and phylogenetic diversity. Biological conservation 61, 1-10 (1992).

66. A. Baselga, Partitioning the turnover and nestedness components of beta diversity. Global ecology and biogeography 19, 134-143 (2010).

67. C. Lozupone, R. Knight, UniFrac: a new phylogenetic method for comparing microbial communities. Appl. Environ. Microbiol. 71, 8228-8235 (2005).

68. H. Akaike, Information theory as an extension of the maximum likelihood principleIn: Second International Symposium on Information Theory (Eds) BN Petrov, F. (Academiai Kiado, Budapest, 1973), pp. pp. 267-281.

69. N. J. Nagelkerke, A note on a general definition of the coefficient of determination. Biometrika 78, 691-692 (1991).

70. A. D. Cliff, J. K. Ord, Spatial processes: models \& applications. (Taylor \& Francis, 1981).

71. A. Baselga, D. Orme, S. Villeger, J. De Bortoli, F. Leprieur, Partitioning beta diversity 
into turnover and nestedness components. Package betapart, Version, 1.4-1 (2017).

72.

A. Baselga, C. D. L. Orme, betapart: an R package for the study of beta diversity. Methods in ecology and evolution 3, 808-812 (2012).

73. R. Bivand, G. Piras. (American Statistical Association, 2015).

74. R. S. Bivand, D. W. Wong, Comparing implementations of global and local indicators of spatial association. Test 27, 716-748 (2018).

75. Y. Reecht, M. J. Rochet, V. M. Trenkel, S. Jennings, J. K. Pinnegar, Use of morphological characteristics to define functional groups of predatory fishes in the Celtic Sea. Journal of fish biology 83, 355-377 (2013).

76. K. O. Winemiller, Ecomorphological diversification in lowland freshwater fish assemblages from five biotic regions. Ecological Monographs 61, 343-365 (1991).

77. K. S. Boyle, M. H. Horn, Comparison of feeding guild structure and ecomorphology of intertidal fish assemblages from central California and central Chile. Marine Ecology Progress Series 319, 65-84 (2006).

78. O. Dumay, P. Tari, J. Tomasini, D. Mouillot, Functional groups of lagoon fish species in Languedoc Roussillon, southern France. Journal of Fish Biology 64, 970-983 (2004).

79. J. S. Lefcheck et al., Dimensions of biodiversity in Chesapeake Bay demersal fishes: patterns and drivers through space and time. Ecosphere 5, 14 (2014).

80. C. Fulton, D. Bellwood, P. Wainwright, The relationship between swimming ability and habitat use in wrasses (Labridae). Marine Biology 139, 25-33 (2001).

81. P. Webb, Body form, locomotion and foraging in aquatic vertebrates. American 

Zoologist 24, 107-120 (1984). 


\section{Acknowledgments}

We thank David Mouillot and two anonymous reviewers for comments on this manuscript. We are grateful to Aurèle Toussaint and Nicolas Charpin for their help in data acquisition. Funding: This work was supported by CEBA, ANR-10-LABX-0025 and TULIP, ANR-10-LABX-41 projects. G.S. was funded by the China Scholarship Council. Author contributions: G.S, S.V. and S.B. designed the study, analyzed the data and wrote the manuscript. G.S., J.X. and S.T. collected and compiled the data, G.S. and M.L. collaborated on the core data preparation and coding in R. All authors led to revising the paper and preparing and approving it for publication.

Competing interests: The authors declare no competing interests. Data and materials availability: Data and materials availability: All data needed to evaluate the conclusions in the paper are present in the paper and/or the Supplementary Materials. Additional data, scripts and files related to this paper are available at https://figshare.com/s/5fadc2c14cbb1f39c25c. 
334 Supplementary Materials:

335 Materials and Methods

336 Figs. S1-S4

$337 \quad$ Table $\mathrm{S} 1$

338 References (44-81)

339 Table S2 (separate file)

340 Table S3 (separate file) 


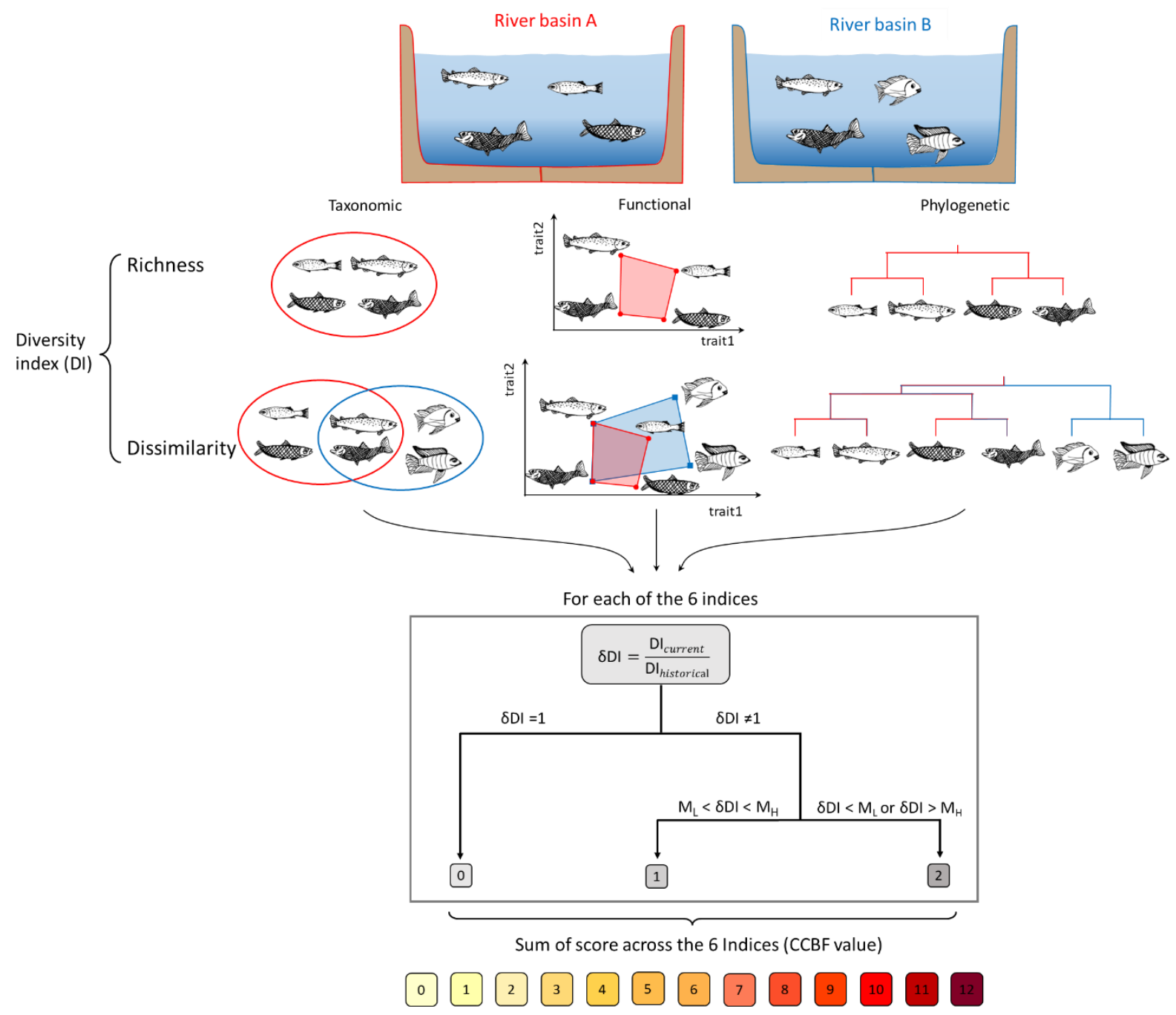

Fig. 1. Framework to measure the cumulative change in biodiversity facets (CCBF). $\delta$ DI

343 represents the change of a single diversity index among the six considered (Taxonomic richness,

344 Functional richness, and Phylogenetic richness within each river basin and Taxonomic

345 dissimilarity, Functional dissimilarity and Phylogenetic dissimilarity between pairs of basins);

$346 \mathrm{M}_{\mathrm{L}}$ is the median of all the values lower than $1, \mathrm{M}_{\mathrm{H}}$ is the median of all the values higher than

347 1. Score is used to compute the CCBF index. 

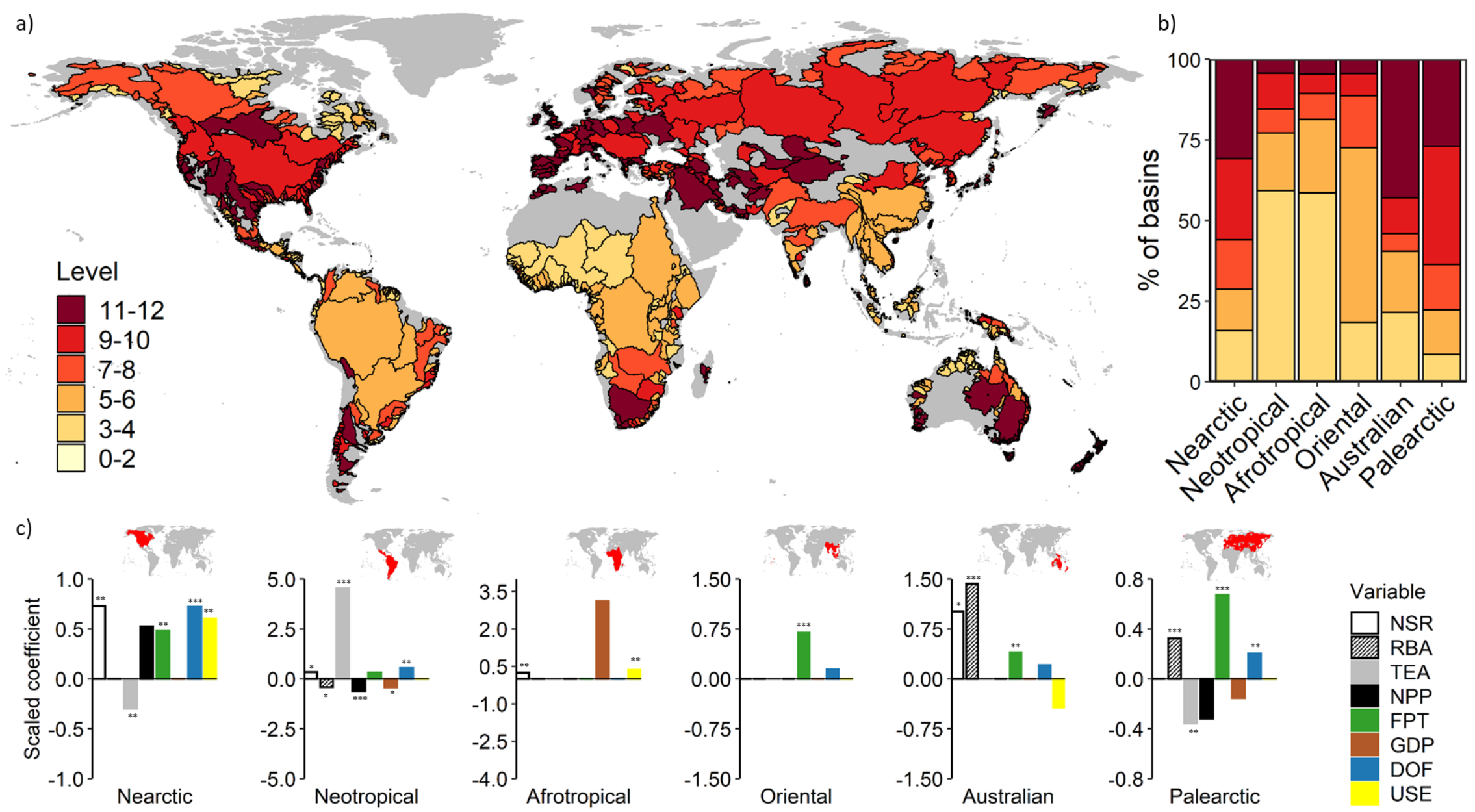

Fig. 2. Cumulative change in biodiversity of freshwater fish faunas. Cumulative index accounts for the sum of the changes in the six diversity 
basins; b) percentage of river basins for six intensities of change in each biogeographic realm; c) scaled coefficient of the eight drivers of biodiversity glacial maximum; NPP: net primary productivity; FPT: human footprint; GDP: gross domestic product; DOF: degree of fragmentation; USE: consumptive water use). Number of river basins used in the models: Afrotropical, n=198; Australian, $\mathrm{n}=525 ;$ Nearctic, $\mathrm{n}=241$; Neotropical, $\mathrm{n}=350$;

Oriental, $\mathrm{n}=292$; Palearctic, $\mathrm{n}=729 .(* * * P<0.001 ; * * P<0.01 ; * P<0.05)$ 
a)

Taxonomic richness change $\left(\mathrm{N}^{+}=1517 ; \mathrm{N}^{0}=887 ; \mathrm{N}^{-}=52\right)$

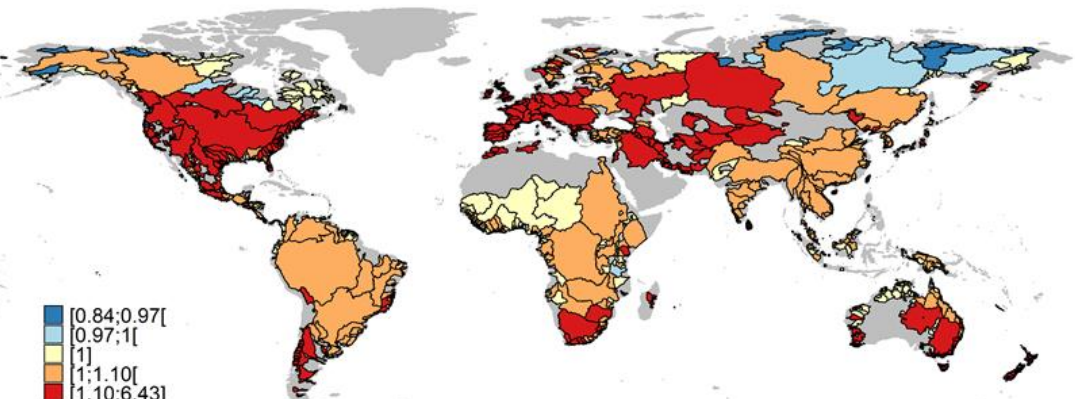

b)

Functional richness change $\left(\mathrm{N}^{+}=1425 ; \mathrm{N}^{0}=962 ; \mathrm{N}^{-}=69\right)$

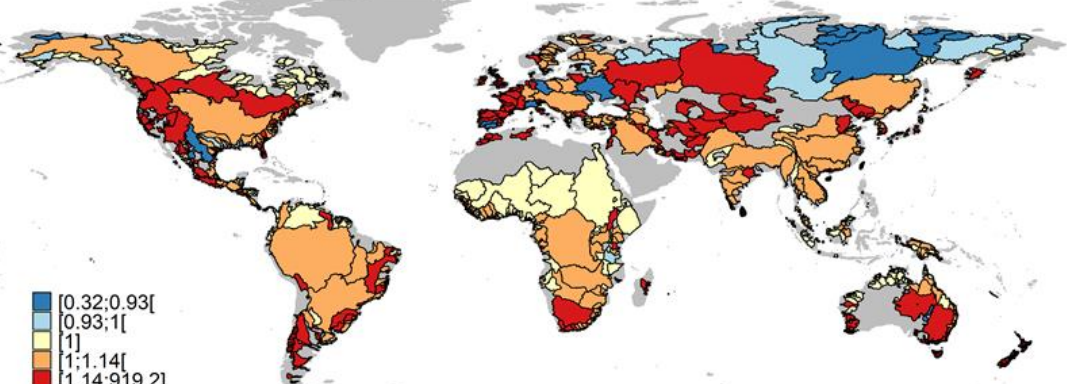

c)
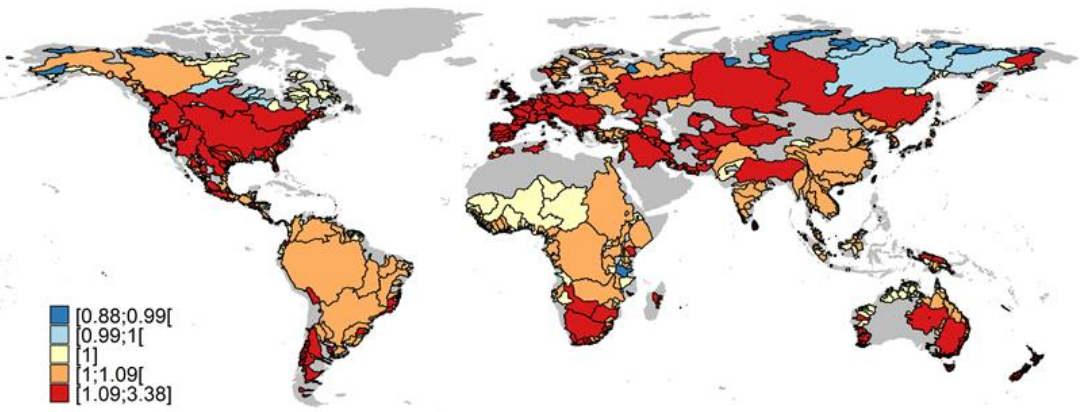

Phylogenetic richness change $\left(N^{+}=1523 ; N^{0}=878 ; N^{-}=55\right)$ d)
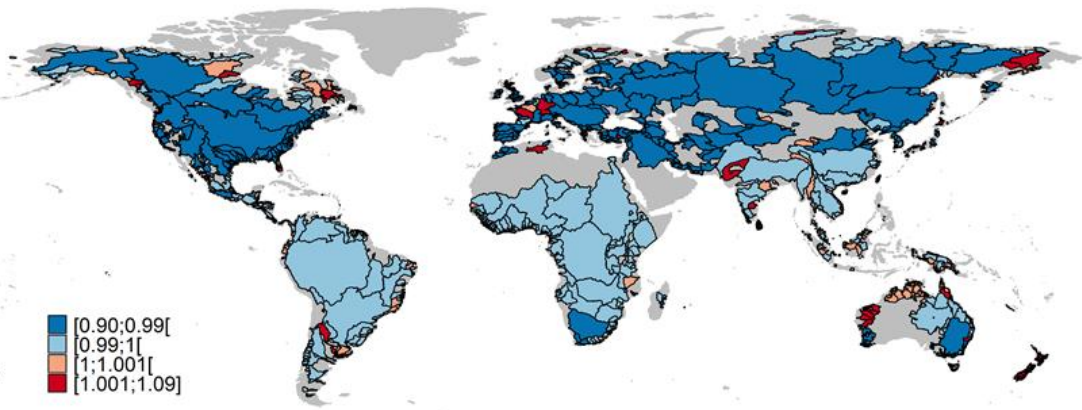

e)

Functional dissimilarity change $\left(\mathrm{N}^{+}=379 ; \mathrm{N}^{0}=0 ; \mathrm{N}^{-}=2077\right)$

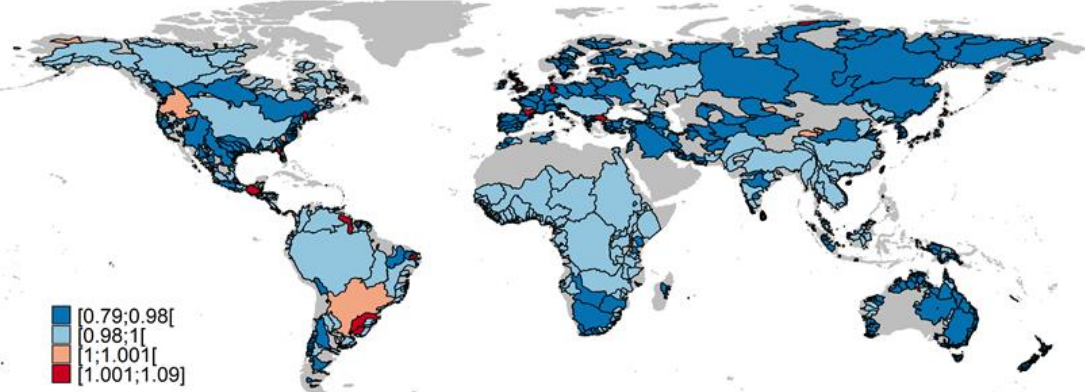

f)

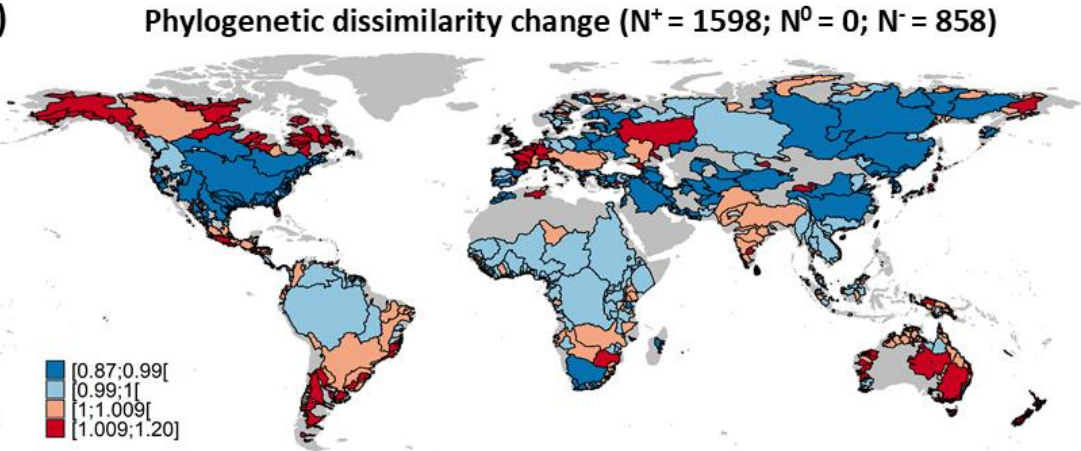


Fig. 3. Changes in each of the six biodiversity indices for the world freshwater fish assemblages (2,456 river basins). a) Taxonomic richness change; b) Functional richness change; c) Phylogenetic richness change; d) Taxonomic dissimilarity change; e) Functional dissimilarity change; f)

Phylogenetic dissimilarity change. Legend values are the original ratio $\mathrm{DI}_{\text {current/ }} / \mathrm{DI}_{\text {historical. }}$ Number of basins where fish diversity increased $\left(\mathrm{N}^{+}\right)$,

remained unchanged $\left(\mathrm{N}^{0}\right)$ or decreased $\left(\mathrm{N}^{-}\right)$are provided at the top of each panel. 
a)

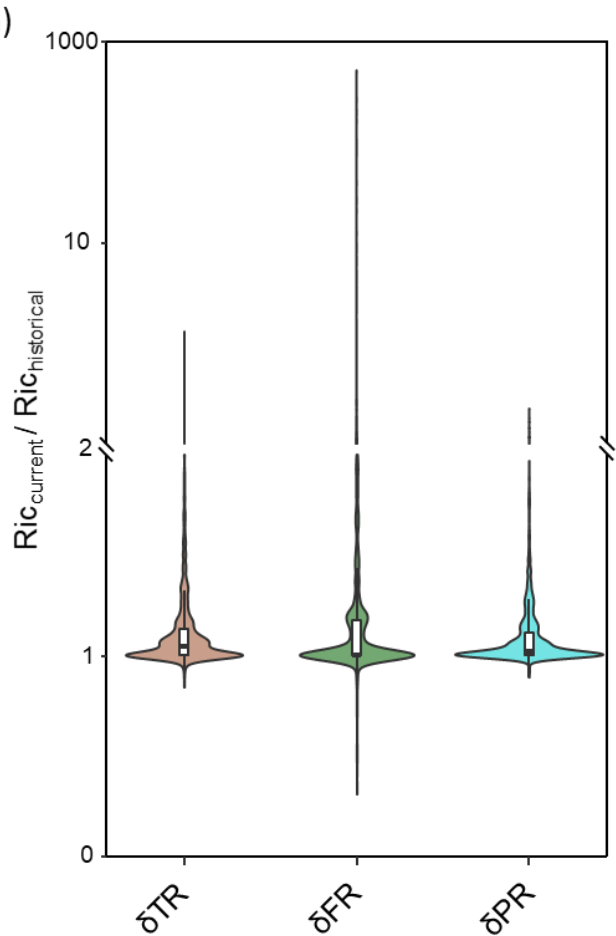

b)

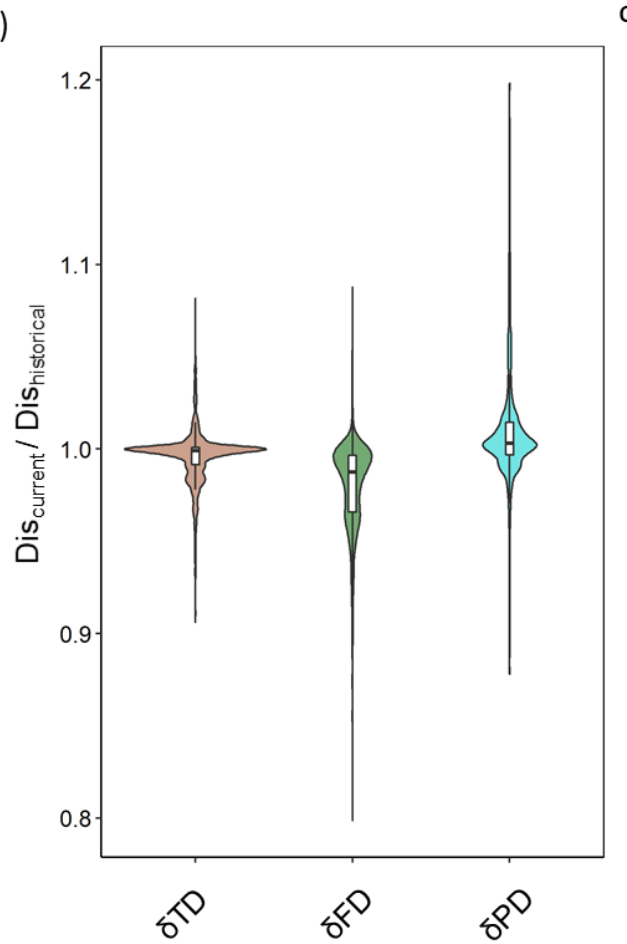

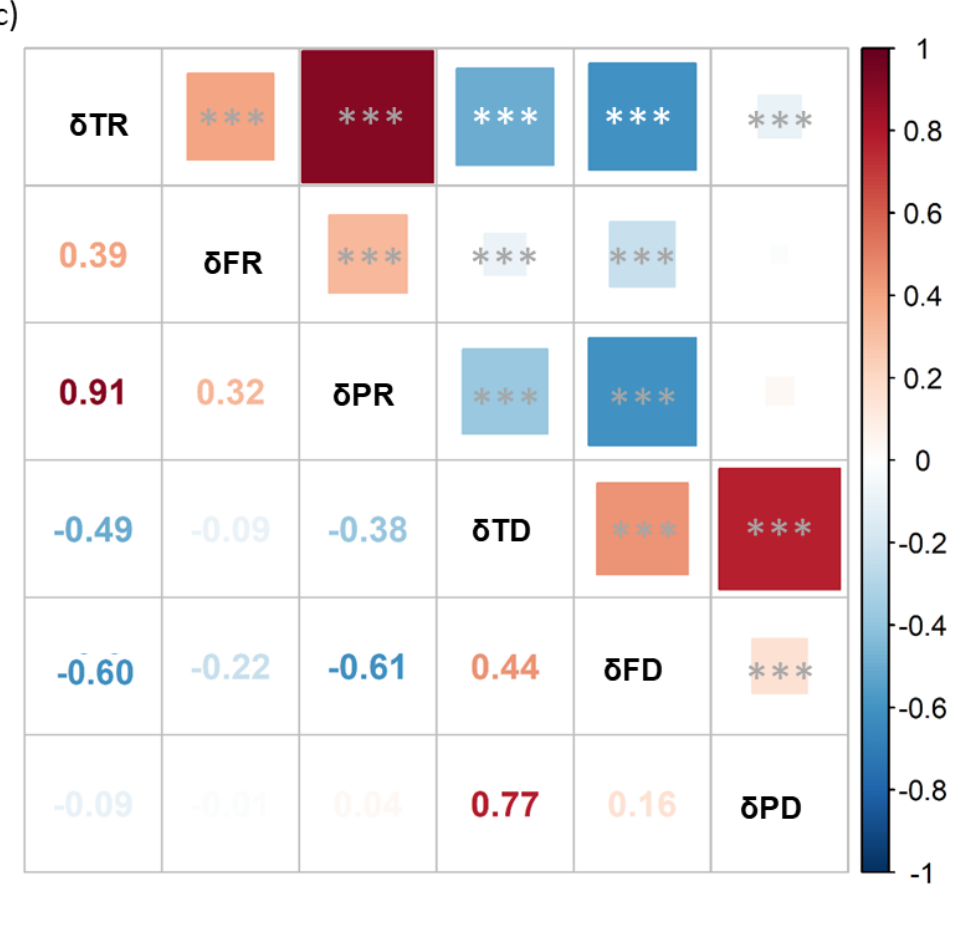

362

Fig. 4. Changes in biodiversity from historical to current period. a) Violin plots show the distribution of the three richness change indices values.

b) Violin plots show the distribution of the three dissimilarity change indices values. c) Pearson correlation between the changes in diversity indices.

(River basin number $=2,456, * * * P<0.001$ ) 


\section{Science \\ DAAAS}

This word file includes:

Figs. S1-S4

Table S1

Other Supplementary Materials for this manuscript include the following: 


\section{Materials and methods}

Occurrence data: We used the most comprehensive database of freshwater fish species distributions across the world [(19) available at http://data.freshwaterbiodiversity.eu]. The fish occurrence database gathers the occurrence of 14,953 species (more than $83 \%$ of the freshwater fish species) in 3,119 drainage basins, covering more than $80 \%$ of the Earth's surface (19). Fish occurrence in each river basin accounts for all the freshwater fish species inhabiting the entire river network of each basin, from $1^{\text {st }}$ order streams to the sea. Each occurrence is paired with a status, either native or non-native established if the species was not historically present in the river basin. Each river basin was assigned to one of the six terrestrial biogeographic realms [i.e., Afrotropical, Australian (including Oceania), Nearctic, Neotropical, Oriental and Palearctic] according to Lévêque et al. (44) and Brosse et al. (45). Historical fish assemblages composition in the river basins refers to only native species, and thus roughly corresponds to the preindustrial period (i.e., before the $18^{\text {th }}$ century), from when industrialization began and fish introductions for aquaculture, fishing, and ornamental purposes sharply increased $(8,46,47)$. Similarly, the current sixth mass extinction rises from the beginning of the industrial period (48). Therefore, despite a few human mediated species introductions and extinctions occurred before the $18^{\text {th }}$ century (e.g., common carp, Cyprinus carpio, introduction in Western Europe), most are more recent. Current fish assemblages composition refers to the non-native species and excludes the local extirpated or extinct native ones. Extirpations refer to the extinction of a fish species within a river basin and data were extracted from the literature reviews of Brosse et al. (45) and Diaz et al. (49). We then updated these data using IUCN Red lists (29). Species with "extinct" or "extinct in the wild" status in the IUCN Red list were thus considered as extinct in their native 
river basins (Table S2). Although species extirpations/extinctions are probably underestimated for a number of reasons such as the time lag between local report of species extinction and validation of extinction over an entire river basin, we here used the most comprehensive and updated information on fish extinction at the river basin scale.

Functional traits: Among the 14,953 species present in the occurrence database, 10,705 species were morphologically described using pictures and drawings from textbooks and scientific websites. Morphology was assessed using ten traits describing the size and shape of body parts involved in food acquisition and locomotion $(19,21)$. The fish size was described using the maximum body length (Max. Body Length) taken from (50). Those maximum body lengths were carefully reviewed, and irrelevant measures have been corrected according to appropriate literature. In addition to size, 11 morphological measures were assessed on side view pictures (Fig. S4a) collected during an extensive literature review including our field data and scientific literature sources made of peer-reviewed articles, books, and scientific websites. We collected at least one picture (photograph or scientific drawing) per species. Only good quality pictures and scientific side view drawings of entire adult animals, with confirmed species identification, were kept. For species with marked sexual dimorphism, we considered male morphology, as female pictures are scarce for most species (especially for Perciformes and Cyprinodontiformes). Intraspecific morphological traits variability was not considered in this study as it hardly affects functional diversity at the large spatial resolution considered (27). The nine unitless traits describing the morphology of the fish head (including mouth and eye), body, pectoral and caudal fins (Fig. S4b) were computed as ratios between 11 morphological measures done using ImageJ software (http://rsb.info.nih.gov/ij/index.html). The 10 
morphological traits ( 9 unitless ratios and body size) selected are commonly used in assessment of fish functional diversity [e.g., (21, 51-53)] and are linked to the feeding and locomotion functions of fish that themselves determine their contribution to key ecosystem processes such as controlling food webs and nutrient cycles (4) (Fig. S4b). The 10 traits were not markedly correlated to each other (Spearman's correlation coefficient, $\mid$ rho $\mid<0.45$ for all the 45 pairwise comparisons). Functional traits not measurable on side pictures, such as gut length, oral gape area and shape, were not included because they are currently only available for a few species in public databases.

Some species have unusual morphologies (species without tails, flatfishes) that prevent from measuring some morphological traits. We thus applied conventions as mentioned in Su et al. (51), Toussaint et al. (21) and Villéger et al. (53) for these few exceptions. Due to the lesion of body parts or the quality of fish pictures, some traits have not been measured for some species. Overall, $24.1 \%$ of the values were missing in the raw morphological traits dataset (from 6.9\% for maximum body length to $31.4 \%$ for relative maxillary length). Those missing values were filled using a phylogenetic generalized linear model $(54,55)$. We then computed a principal component analysis (PCA) using values of the 10 morphological traits for all the species. We selected the first four PCA axes, which explained $68.2 \%$ of the total variance among the world's fish functions, to compute the functional diversity indices.

Phylogenetic diversity: Phylogenetic distances between all species were computed on the tree from Rabosky et al. (56), including 31,526 marine and freshwater ray-finned fishes. This dataset is based on 11,638 species whose position was estimated from genetic data; the remaining 19,888 species were placed in the tree using stochastic polytomy resolution (56). 
Environmental and Anthropogenic variables: We selected four environmental and four anthropogenic variables as proxies of the main processes responsible from native biodiversity and impacts of human activities on freshwater ecosystems: (i) NSR: native species richness. (ii) RBA: river basin area; (iii) NPP: net primary productivity; (iv) TEA: temperature anomaly from the Last Glacial Maximum to the present; (v) DOF: degree of fragmentation; (vi) FPT: human footprint; (vii) GDP: gross domestic product; and (viii) USE: consumptive water use. These 8 metrics were overall independent of each other $(\mid$ Pearson's $r \mid<0.5)$, to the exception of NSR and RBA (Fig. S3).

NSR accounts for the biotic resistance hypothesis, which assumes a higher resistance of species rich assemblages against disturbances (40). RBA, NPP and TEA were from Tedesco et al. (19), and account for the three main hypotheses explaining biodiversity, namely the speciesarea hypothesis that predicts a positive relationship between river basin area and biodiversity; the species-energy hypothesis that predicts higher biodiversity in energy rich areas, and the historical contingency, which has largely been influenced by the last glacial events in freshwater fish (57-60).

FPT is a comprehensive representation of anthropogenic threats to biodiversity, which cumulatively accounts for eight human pressures—built environments, croplands, pasture lands, human population density, night lights, railways, major roadways and navigable waterways (23). FPT dataset (resolution: $1 \mathrm{~km}^{2}$ ) was taken from Venter et al. (23). GDP measures the size of the economy and is defined as the market value of all final goods and services produced within a region in a given period $(61,62)$. GDP dataset (1 square degree resolution) was taken from Nordhaus \& Chen (61). 
DOF accounts for the degree to which river networks are fragmented longitudinally by infrastructure, such as hydropower and irrigation dams (32). DOF dataset (resolution: $500 \mathrm{~m}^{2}$ ) was taken from Grill et al. (32).

USE accounts for water consumption for irrigation, industry, municipal uses and water transfer to other river systems. USE (resolution: $1 \mathrm{~km}^{2}$ ) for each river basin was calculated by using $100 *\left(d_{\text {nat }}-d_{\text {ant }}\right) / d_{\text {nat }}$, where $d_{\text {nat }}$ represents the total amount of long-term discharge without human influences in each river basin and $\mathrm{d}_{\text {ant }}$ represents the total amount of average long-term discharge after human extractions and use in each river basin. $d_{\text {ant }}$ and $d_{\text {nat }}$ were both taken from the WaterGAP model $(32,63)$.

We mapped FTP, GDP, DOF and USE by their relative resolution grid data over the basinscale map and then calculated the mean value of all the cells covered by each basin. Here we considered the 2,335 river basins (out of the 3,119) with available values for both CCBF (see below) and the eight environmental and anthropogenic variables.

Measuring temporal changes in biodiversity of freshwater fishes: Among the 3,119 river basins with fish occurrence data, diversity indices were measured for all basins with more than 5 fish species to meet the requirements of functional diversity calculation, leading to consider a total of 2,456 river basins. 10,682 species were obtained after matching the occurrence, functional and phylogenetic databases. We assessed the 6 facets of biodiversity (Fig. 1) for fish assemblage inhabiting each of the 2,456 river basins for the current and historical period: taxonomic richness (TR) measured as the number of species, functional richness (FR) measured as the volume of the functional space occupied by an assemblage [i.e., the volume of the minimum convex hull in the functional space which includes all the species in the assemblage, 
491

492

(64)], and phylogenetic richness (PR) as the total length of branches linking all species from the assemblage on the phylogenetic tree (65). In addition to these indices describing diversity within each assemblage (i.e., alpha-diversity), we also accounted for the dissimilarity among assemblages (i.e., beta-diversity). More specifically, we quantified taxonomic, functional and phylogenetic dissimilarity between each pair of fish assemblages from the same realm as the proportion of total richness in the pair that is not shared by the assemblages, [i.e., Jaccard-index for taxonomic dissimilarity (66), beta-FRic for functional dissimilarity (64) and UniFrac for phylogenetic dissimilarity (67)]. Then the average value of dissimilarity between a fish assemblage and all the other assemblages from the same realm was computed to get for each river basin values of taxonomic dissimilarity (TD), functional dissimilarity (FD), and phylogenetic dissimilarity (PD).

We then calculated for each of these six diversity indices the temporal change ( $\delta \mathrm{DI})$ as the ratio: $\mathrm{DI}_{\text {current }} / \mathrm{DI}_{\text {historical }}$ We then computed score for each $\delta \mathrm{DI}$ according to its values: If $\delta \mathrm{DI}$ $=1$, it scores 0 ; if $\delta \mathrm{DI}$ is higher than the median of all the values lower than 1 and lower than the median of all the values higher than 1, it scores 1 ; and if $\delta \mathrm{DI}$ is lower than the median of all the values lower than 1 or higher than the median of all the values higher than 1 , it scores 2 . Then we sum up the scores of the six $\delta$ DI for each basin to get the index of cumulative changes in biodiversity facets which ranges from 0 to 12 (CCBF, Fig. 1).

Thus, our cumulative index accounts for all marked changes in biodiversity facets, not only species loss. Null values are possible only if taxonomic, functional and phylogenetic composition of all assemblages from a realm remained unchanged because otherwise all dissimilarity indices are changed. $\mathrm{CCBF}$ scores from 0 to 6 account for moderate changes in 
biodiversity for all the six facets (all the 6 facets scoring 0 or 1 ) or strong changes for no more than half of the facets (no more than 3 facets scoring 2). Such CCBF values are considered as moderate changes in biodiversity. CCBF scores from 7 to 12 account for strong changes in biodiversity with all 6 facets changes or more than half of the facets scoring 2. See table S3 for the six diversity indices and CCBF scores for the 2,456 basins.

Statistical analyses: To assess how environmental processes and human activities contributed to the observed change in biodiversity in each realm, we quantified the relative contribution of NSR, RBA, TEA, NPP, FPT, GDP, DOF and USE to the CCBF values of the 2,335 river basins for which all variables were available, using spatial simultaneous autoregressive error models

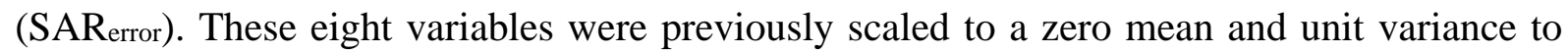
ensure equal weighting in the models. We first ran the null model (intercept-only) with none of the variables as a reference. Then we used stepwise regression to select the best models by AIC (Akaike's Information Criterion). We eventually selected the model with the lowest AIC (68) (Table S2). We used Nagelkerke's R2 (69) as the pseudo R-squared to qualify the final models' performance. After model fitting, we checked for broad spatial autocorrelation in model residuals by computing the Moran's I statistic (70).

All statistical analyses were performed with the $\mathrm{R}$ software environment version 3.3 ( $R$ Core Team), including the library 'RPhylopars' (55) for filling the missing values in the trait database, 'betapart' for computing dissimilarity indices $(71,72)$, 'spatialreg' and 'spdep' for developing SAR error models (73) and performing Moran's I tests (74). 


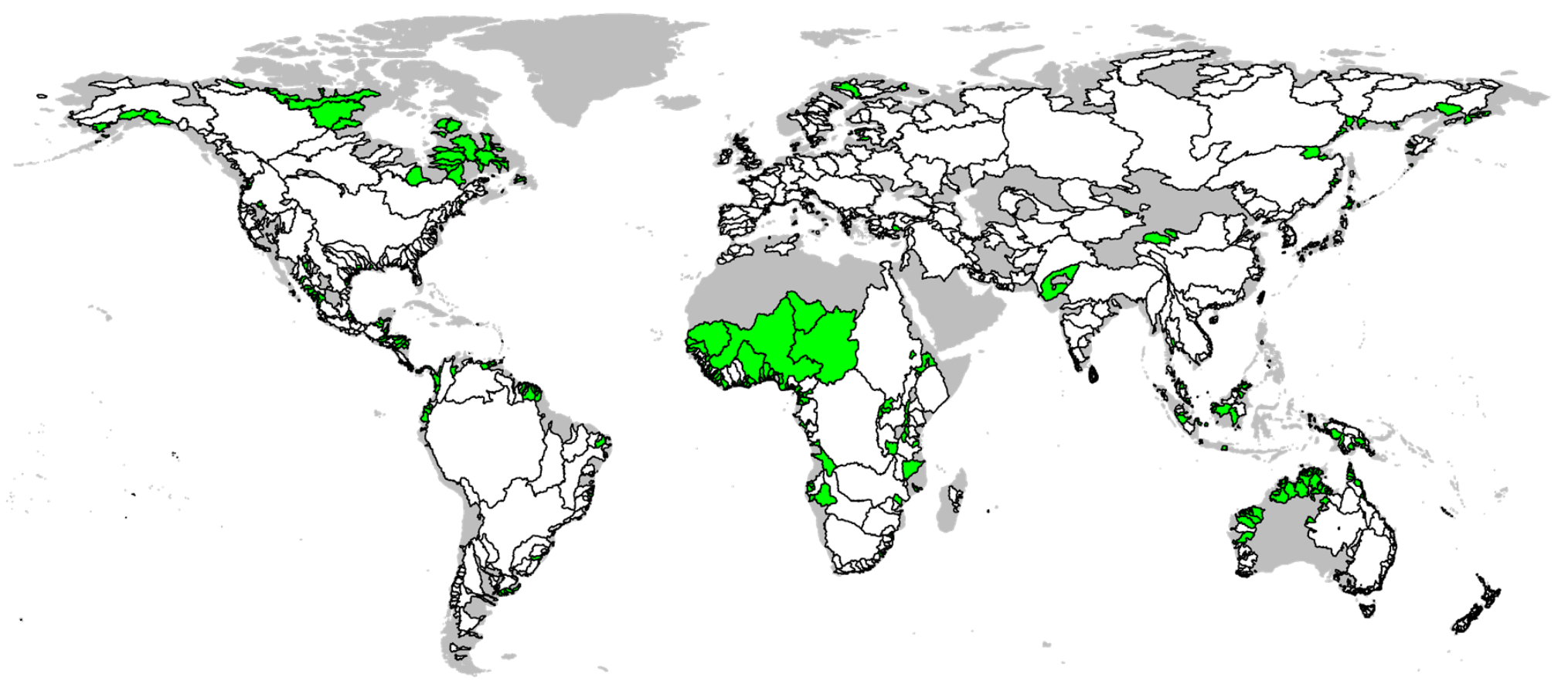

\begin{tabular}{lccccccc} 
& Nearctic & Neotropical & Afrotropical & Oriental & Australian & Palearctic & World \\
\hline Number of basin without changes in richness & 76 & 225 & 116 & 97 & 198 & 166 & 878 \\
Percentage of basin number (\%) & 31.54 & 60 & 57.43 & 28.87 & 37.08 & 21.61 & 35.75 \\
Percentage of basin area (\%) & 11.45 & 5.6 & 34.9 & 10.06 & 26.65 & 1.94 & 13.4 \\
Percentage of river length (\%) & 12.77 & 6.02 & 34.7 & 11.15 & 27.21 & 2.05 & 13.42 \\
\hline
\end{tabular}

Fig. S1.

River basins (green color) where the three richness diversity facets remained unchanged from historical to current period. 


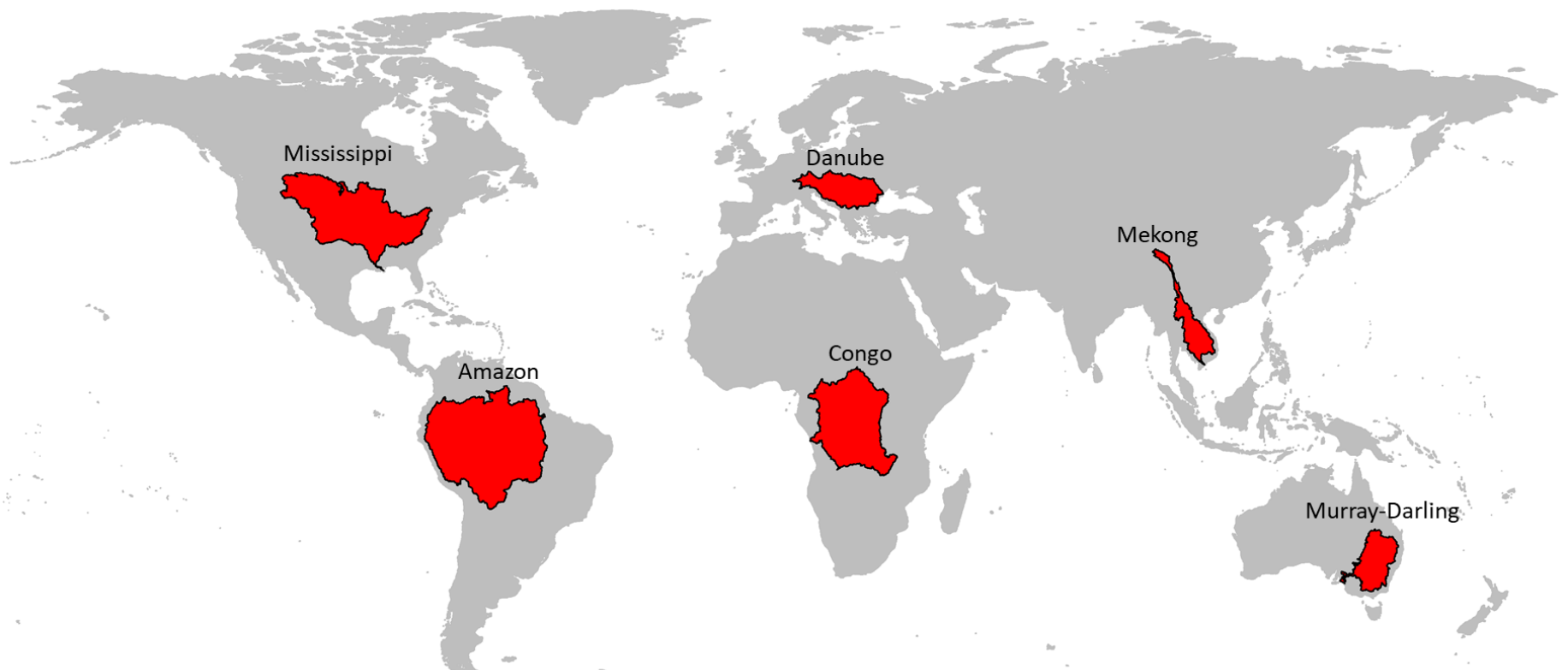

\begin{tabular}{lccccccc} 
Basin names & $\delta \mathrm{TR}$ & $\delta \mathrm{FR}$ & $\delta \mathrm{PR}$ & $\delta \mathrm{TD}$ & $\delta \mathrm{FD}$ & $\delta \mathrm{PD}$ & $\mathrm{CCBF}$ \\
\hline Amazon & 1.0026 & 1.0003 & 1.0036 & 0.9997 & 0.9980 & 0.9991 & 6 \\
Congo & 1.0073 & 1.0061 & 1.0122 & 0.9991 & 0.9952 & 0.9989 & 6 \\
Mekong & 1.0346 & 1.0061 & 1.0394 & 0.9977 & 0.9958 & 0.9973 & 6 \\
Danube & 1.2247 & 1.1238 & 1.1865 & 0.9797 & 0.9937 & 1.0051 & 9 \\
Mississippi & 1.1523 & 1.0727 & 1.1863 & 0.9802 & 0.9955 & 0.9885 & 10 \\
Murray-Darling & 1.2642 & 1.1458 & 1.2800 & 0.9906 & 0.9714 & 1.0189 & 11 \\
\hline
\end{tabular}

538

Fig. S2.

540 Changes in freshwater fish biodiversity for 6 representative river basins over the world. $\delta \mathrm{TR}$ : taxonomic richness change; $\delta$ FR: functional richness 
542 dissimilarity change. CCBF is the index of cumulative change in biodiversity facets. 


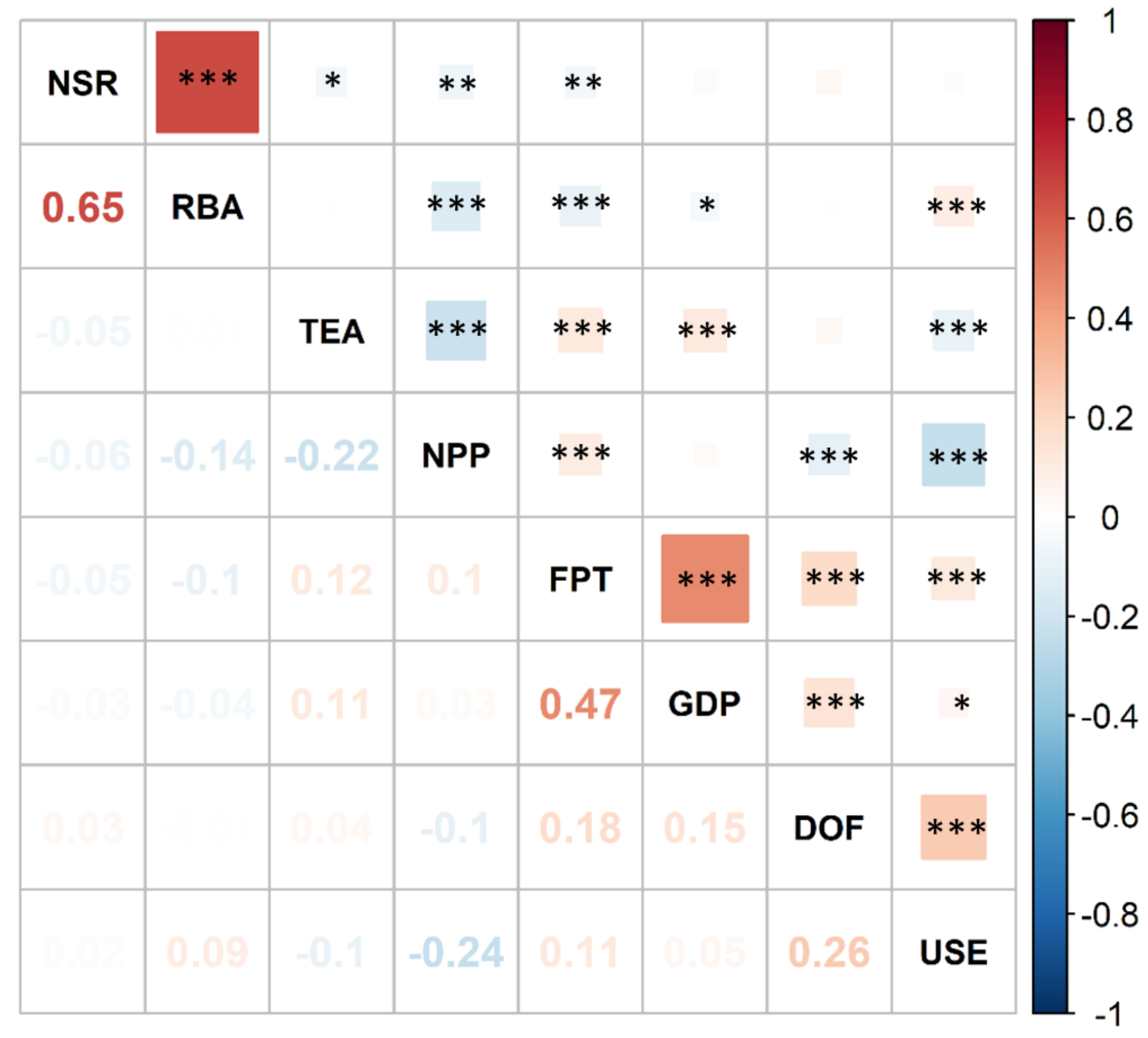

$544 \quad$ Fig. S3.

545 Pearson correlation between the eight environmental and human activity variables of the world

546 river basins $(n=2,335)$. NSR: native species richness; RBA: river basin area; TEA: temperature

547 anomaly since the last glacial maximum; NPP: net primary productivity; FPT: human footprint;

548 GDP: gross domestic product; DOF: degree of fragmentation; USE: consumptive water use.

$549 \quad(* * * P<0.001, * * P<0.01, * P<0.05)$ 


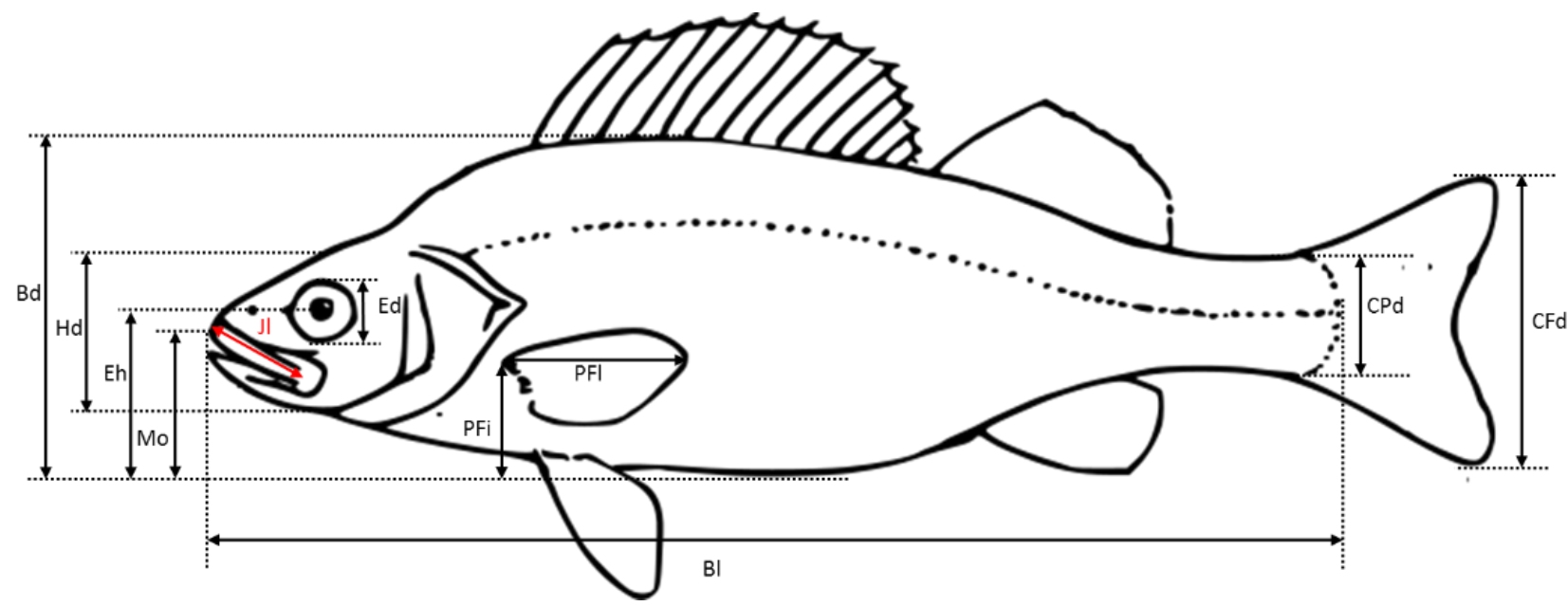

a. Morphological measurements

\begin{tabular}{|c|c|c|}
\hline Code & Name & Protocol for measurement \\
\hline Blmax & $\begin{array}{l}\text { Maximum Body } \\
\text { length }\end{array}$ & Maximum adult length \\
\hline $\mathrm{B} 1$ & Body length & Standard length (snout to caudal fin basis) \\
\hline $\mathrm{Bd}$ & Body depth & Maximum body depth \\
\hline $\mathrm{Hd}$ & Head depth & Head depth at the vertical of eye \\
\hline $\mathrm{CPd}$ & $\begin{array}{l}\text { Caudal peduncle } \\
\text { depth }\end{array}$ & Minimum depth of the caudal peduncle \\
\hline $\mathrm{CFd}$ & Caudal fin depth & Maximum depth of the caudal fin \\
\hline Ed & Eye diameter & Vertical diameter of the eye \\
\hline Eh & Eye position & $\begin{array}{l}\text { Vertical distance between the centre of the eye to the bottom } \\
\text { of the body }\end{array}$ \\
\hline Mo & Oral gape position & $\begin{array}{l}\text { Vertical distance from the top of the mouth to the bottom of } \\
\text { the body }\end{array}$ \\
\hline $\mathrm{Jl}$ & $\begin{array}{l}\text { Maxillary jaw } \\
\text { length }\end{array}$ & Length from snout to the corner of the mouth \\
\hline $\mathrm{PFl}$ & Pectoral fin length & Length of the longest ray of the pectoral fin \\
\hline $\mathrm{PFi}$ & $\begin{array}{l}\text { Pectoral fin } \\
\text { position }\end{array}$ & $\begin{array}{l}\text { Vertical distance between the upper insertion of the pectoral } \\
\text { fin to the bottom of the body }\end{array}$ \\
\hline
\end{tabular}

All measurements were made on pictures except Blmax values, which were downloaded from Fishbase.org 
b. Morphological traits

\begin{tabular}{|c|c|c|c|}
\hline Morphological traits & Formula & Potential link with fish functions & References \\
\hline Maximum body length & BLmax & $\begin{array}{l}\text { Size is linked to metabolism, trophic } \\
\text { impacts, locomotion ability, nutrient } \\
\text { cycling }\end{array}$ & $(21)$ \\
\hline Body elongation & $\frac{B l}{B d}$ & Hydrodynamism & $(75)$ \\
\hline Eye vertical position & $\frac{E h}{B d}$ & $\begin{array}{l}\text { Position of fish and/or of its prey in } \\
\text { the water column }\end{array}$ & (76) \\
\hline Relative eye size & $\frac{E d}{H d}$ & Visual acuity & $(77)$ \\
\hline Oral gape position & $\frac{M o}{B d}$ & $\begin{array}{l}\text { Feeding position in the water } \\
\text { column }\end{array}$ & $(78,79)$ \\
\hline $\begin{array}{l}\text { Relative maxillary } \\
\text { length }\end{array}$ & $\frac{J l}{H d}$ & Size of mouth and strength of jaw & $(21)$ \\
\hline Body lateral shape & $\frac{H d}{B d}$ & Hydrodynamism and head size & $(21)$ \\
\hline $\begin{array}{l}\text { Pectoral fin vertical } \\
\text { position }\end{array}$ & $\frac{P F i}{B d}$ & Pectoral fin use for swimming & $(78)$ \\
\hline Pectoral fin size & $\frac{P F l}{B l}$ & Pectoral fin use for swimming & $(80)$ \\
\hline $\begin{array}{l}\text { Caudal peduncle } \\
\text { throttling }\end{array}$ & $\frac{C F d}{C P d}$ & $\begin{array}{l}\text { Caudal propulsion efficiency } \\
\text { through reduction of drag }\end{array}$ & $(81)$ \\
\hline
\end{tabular}

$552 \quad$ Fig. S4.

553 Morphological measurements (a) and morphological traits (b) measured on each fish species.

554 For each morphological trait, the potential link with food acquisition and locomotion and

555 associated references are provided. 
557 Results of the spatial simultaneous autoregressive error models (SAR error) showing the 558 coefficients of the selected optimal model in each realm. Model with the lowest AIC was 559 selected for each realm. (NSR: native species richness; RBA: river basin area; TEA: 560 temperature anomaly since the last glacial maximum; NPP: net primary productivity; FPT:

561 human footprint; GDP: gross domestic product; DOF: degree of fragmentation; USE:

562 consumptive water use; AIC: Akaike's Information Criterion). The Moran's I value represents

563 the remaining autocorrelation on the residuals of the model for the first distance class (i.e., 564 neighbor drainages) in each realm.

\section{Nearctic $(\mathbf{n}=\mathbf{2 4 1})$}

\begin{tabular}{lrrr} 
NULL Model & & AIC $=1416.66$ \\
Initial Model: NSR+RBA+TEA+NPP+FPT+GDP+DOF+USE & & AIC $=1116.66$ \\
Optimal Model:NSR+TEA+NPP+FPT+DOF+USE & & AIC = 1113.68 \\
Statistics in Optimal Model & coefficient (SE) & z-value & P \\
\hline NSR & $0.73(0.3)$ & 2.433 & $\mathbf{0 . 0 1 5}$ \\
TEA & $-0.297(0.139)$ & -2.139 & $\mathbf{0 . 0 3 2 5}$ \\
NPP & & & 0.0768 \\
FPT & $0.526(0.297)$ & 1.769 & $\mathbf{0 . 0 0 9 9}$ \\
DOF & $0.482(0.187)$ & 2.581 & $\mathbf{0 . 0 0 0 2}$ \\
USE & $0.722(0.197)$ & 3.667 & $\mathbf{0 . 0 0 2 1}$ \\
\hline Nagelkerke's R2 & $0.604(0.196)$ & 3.077 & \\
Moran's I & 0.353 & & \\
\hline
\end{tabular}


Neotropical $(n=350)$

NULL Model

$\mathrm{AIC}=1578.34$

Initial Model: NSR+RBA+TEA+NPP+FPT+GDP+DOF+USE

$\mathrm{AIC}=1546.92$

Optimal Model: NSR+RBA+TEA+NPP+FPT+GDP+DOF

$\mathrm{AIC}=1544.92$

Statistics in Optimal Model

coefficient (SE) z-value

$P$

\begin{tabular}{lccc}
\hline NSR & $0.344(0.142)$ & 2.421 & $\mathbf{0 . 0 1 5 5}$ \\
RBA & $-0.412(0.168)$ & -2.45 & $\mathbf{0 . 0 1 4 3}$ \\
TEA & $4.54(1.166)$ & 3.893 & $\mathbf{0 . 0 0 0 1}$ \\
NPP & & $\mathbf{0 . 0 0 0 9}$ \\
FPT & $-0.63(0.189)$ & -3.331 & 0.0907 \\
GDP & $0.32(0.189)$ & 1.692 & $\mathbf{0 . 0 2 3 5}$ \\
DOF & $-0.434(0.192)$ & -2.265 & $\mathbf{0 . 0 0 8 5}$ \\
\hline Nagelkerke's R2 & & 2.632 \\
\hline
\end{tabular}


Afrotropical (n=198)

NULL Model

$\mathrm{AIC}=831.50$

Initial Model: NSR+RBA+TEA+NPP+FPT+GDP+DOF+USE

$\mathrm{AIC}=827.53$

Optimal Model: NSR+GDP+USE

$\mathrm{AIC}=\mathbf{8 2 1 . 1 1}$

\begin{tabular}{lccr}
\hline Statistics in Optimal Model & coefficient (SE) & z-value & $P$ \\
\hline NSR & $0.247(0.09)$ & 2.749 & $\mathbf{0 . 0 0 6}$ \\
GDP & $3.108(1.598)$ & 1.945 & 0.0518 \\
USE & $0.355(0.127)$ & 2.799 & $\mathbf{0 . 0 0 5 1}$ \\
\hline Nagelkerke's R2 & 0.444 & \\
Moran's I & -0.044 & & n.s. \\
\hline
\end{tabular}

566

Oriental $(n=292)$

NULL Model

$\mathrm{AIC}=1154.37$

Initial Model: NSR+RBA+TEA+NPP+FPT+GDP+DOF+USE

$\mathrm{AIC}=1146.19$

Optimal Model: FPT+DOF

$\mathrm{AIC}=1137.89$

Statistics in Optimal Model

coefficient (SE)

z-value

$P$

FPT

0.695(0.149) $\quad 4.675$

$<0.0001$

DOF

$0.144(0.083)$

1.739

0.082

Nagelkerke's R2

0.246

Moran's I

$-0.003$

n.s. 


\section{Australian (n=525)}

NULL Model

$\mathrm{AIC}=2382.61$

Initial Model: NSR+RBA+TEA+NPP+FPT+GDP+DOF+USE

$\mathrm{AIC}=2361.76$

Optimal Model: NSR+RBA+FPT+DOF+USE

$\mathrm{AIC}=2357.49$

Statistics in Optimal Model

coefficient (SE)

z-value

$P$

\begin{tabular}{|c|c|c|c|}
\hline NSR & $1.015(0.474)$ & 2.143 & 0.0321 \\
\hline RBA & $1.43(0.328)$ & 4.365 & $<0.0001$ \\
\hline FPT & $0.4(0.182)$ & 2.194 & 0.0282 \\
\hline DOF & $0.208(0.122)$ & 1.701 & 0.0889 \\
\hline USE & $-0.43(0.289)$ & -1.489 & 0.1366 \\
\hline
\end{tabular}

Nagelkerke's R2

0.529

Moran's I

$-0.12$

n.s. 
Palearctic $(n=729)$

NULL Model

$\mathrm{AIC}=3161.83$

Initial Model: $\quad \mathrm{NSR}+\mathrm{RBA}+\mathrm{TEA}+\mathrm{NPP}+\mathrm{FPT}+\mathrm{GDP}+\mathrm{DOF}+\mathrm{USE}$

$\mathrm{AIC}=3101.15$

Optimal Model: RBA+TEA+NPP+FPT+GDP+DOF

$\mathrm{AIC}=3097.47$

Statistics in Optimal Model

coefficient (SE)

z-value

$P$

RBA

$0.324(0.069)$

4.673

$<0.0001$

TEA

$-0.356(0.126) \quad-2.835$

0.0046

NPP

$-0.319(0.181)$

$-1.761$

0.0783

FPT

$0.671(0.112)$

5.999

$<0.0001$

GDP

$-0.155(0.086)$

$-1.808$

0.0706

DOF

$0.206(0.063)$

3.28

0.001

Nagelkerke's R2

0.38

Moran's I

$-0.047$

n.s. 


\section{References (44-81)}

44. C. Lévêque, T. Oberdorff, D. Paugy, M. Stiassny, P. Tedesco, Global diversity of fish (Pisces) in freshwater. Hydrobiologia 595, 545-567 (2008).

45. S. Brosse et al., Fish-SPRICH: a database of freshwater fish species richness throughout the World. Hydrobiologia 700, 343-349 (2013).

46. H. Seebens et al., No saturation in the accumulation of alien species worldwide. Nature communications 8, 14435 (2017).

47. S. Blanchet et al., Non - native species disrupt the worldwide patterns of freshwater fish body size: implications for Bergmann's rule. Ecology Letters 13, 421-431 (2010).

48. G. Ceballos, P. R. Ehrlich, R. Dirzo, Biological annihilation via the ongoing sixth mass extinction signaled by vertebrate population losses and declines. Proceedings of the national academy of sciences 114, E6089-E6096 (2017).

49. M. S. Dias et al., Anthropogenic stressors and riverine fish extinctions. Ecological indicators 79, 37-46 (2017).

50. R. Froese, D. Pauly. (2018), vol. http://www.fishbase.org.

51. G. Su, S. Villéger, S. Brosse, Morphological diversity of freshwater fishes differs between realms, but morphologically extreme species are widespread. Global Ecology and Biogeography 28, 211-221 (2019).

52. D. Bellwood, C. Goatley, S. Brandl, O. Bellwood, Fifty million years of herbivory on coral reefs: fossils, fish and functional innovations. Proceedings of the Royal Society B: Biological Sciences 281, 20133046 (2014).

53. S. Villéger, J. R. Miranda, D. F. Hernandez, D. Mouillot, Contrasting changes in 
taxonomic vs. functional diversity of tropical fish communities after habitat degradation. Ecological Applications 20, 1512-1522 (2010).

54. C. Penone et al., Imputation of missing data in life - history trait datasets: which approach performs the best? Methods in Ecology and Evolution 5, 961-970 (2014).

55. J. Bruggeman, J. Heringa, B. W. Brandt, PhyloPars: estimation of missing parameter values using phylogeny. Nucleic acids research 37, W179-W184 (2009).

56. D. L. Rabosky et al., An inverse latitudinal gradient in speciation rate for marine fishes. Nature 559, 392 (2018).

57. F. Leprieur et al., Partitioning global patterns of freshwater fish beta diversity reveals contrasting signatures of past climate changes. Ecology letters 14, 325-334 (2011).

58. D. J. Currie et al., Predictions and tests of climate - based hypotheses of broad - scale variation in taxonomic richness. Ecology letters 7, 1121-1134 (2004).

59. M. Dynesius, R. Jansson, Evolutionary consequences of changes in species' geographical distributions driven by Milankovitch climate oscillations. Proceedings of the National Academy of Sciences 97, 9115-9120 (2000).

60. J.-F. Guégan, S. Lek, T. Oberdorff, Energy availability and habitat heterogeneity predict global riverine fish diversity. Nature 391, 382-384 (1998).

61. W. Nordhaus, X. Chen, Global gridded geographically based economic data (G-econ), version 4. NASA Socioeconomic Data and Applications Center (SEDAC), (2016).

62. W. D. Nordhaus, Geography and macroeconomics: New data and new findings. Proceedings of the National Academy of Sciences 103, 3510-3517 (2006).

63. P. Döll, S. Siebert, Global modeling of irrigation water requirements. Water resources 
research 38, 8-1-8-10 (2002).

615

64. S. Villéger, N. W. H. Mason, D. Mouillot, New multidimensional functional diversity indices for a multifaceted framework in functional ecology. Ecology 89, 2290-2301 (2008).

65. D. P. Faith, Conservation evaluation and phylogenetic diversity. Biological conservation 61, 1-10 (1992).

66. A. Baselga, Partitioning the turnover and nestedness components of beta diversity. Global ecology and biogeography 19, 134-143 (2010).

67. C. Lozupone, R. Knight, UniFrac: a new phylogenetic method for comparing microbial communities. Appl. Environ. Microbiol. 71, 8228-8235 (2005).

68. H. Akaike, Information theory as an extension of the maximum likelihood principleIn: Second International Symposium on Information Theory (Eds) BN Petrov, F. (Academiai Kiado, Budapest, 1973), pp. pp. 267-281.

69. N. J. Nagelkerke, A note on a general definition of the coefficient of determination. Biometrika 78, 691-692 (1991).

70. A. D. Cliff, J. K. Ord, Spatial processes: models \& applications. (Taylor \& Francis, 1981).

71. A. Baselga, D. Orme, S. Villeger, J. De Bortoli, F. Leprieur, Partitioning beta diversity into turnover and nestedness components. Package betapart, Version, 1.4-1 (2017).

72. A. Baselga, C. D. L. Orme, betapart: an R package for the study of beta diversity. Methods in ecology and evolution 3, 808-812 (2012).

73. R. Bivand, G. Piras. (American Statistical Association, 2015). 
74. R. S. Bivand, D. W. Wong, Comparing implementations of global and local indicators of spatial association. Test 27, 716-748 (2018).

75. Y. Reecht, M. J. Rochet, V. M. Trenkel, S. Jennings, J. K. Pinnegar, Use of morphological characteristics to define functional groups of predatory fishes in the Celtic Sea. Journal of fish biology 83, 355-377 (2013).

76. K. O. Winemiller, Ecomorphological diversification in lowland freshwater fish assemblages from five biotic regions. Ecological Monographs 61, 343-365 (1991).

77. K. S. Boyle, M. H. Horn, Comparison of feeding guild structure and ecomorphology of intertidal fish assemblages from central California and central Chile. Marine Ecology Progress Series 319, 65-84 (2006).

78. O. Dumay, P. Tari, J. Tomasini, D. Mouillot, Functional groups of lagoon fish species in Languedoc Roussillon, southern France. Journal of Fish Biology 64, 970-983 (2004).

79. J. S. Lefcheck et al., Dimensions of biodiversity in Chesapeake Bay demersal fishes: patterns and drivers through space and time. Ecosphere 5, 14 (2014).

80. C. Fulton, D. Bellwood, P. Wainwright, The relationship between swimming ability and habitat use in wrasses (Labridae). Marine Biology 139, 25-33 (2001).

81. P. Webb, Body form, locomotion and foraging in aquatic vertebrates. American Zoologist 24, 107-120 (1984). 
657 Species extirpations/extinctions and introductions in each of the 2456 river basins.

Table S3. (separate file)

659 The changes in the six diversity indices and the index of cumulative change in biodiversity

660 facets for the fish faunas in 2,456 basins. $\delta \mathrm{TR}$ : change in taxonomic richness; $\delta \mathrm{FR}$ : change in

661 functional richness; $\delta$ PR: change in phylogenetic richness; $\delta$ TD: change in taxonomic

662 dissimilarity; $\delta$ FD: change in functional dissimilarity; $\delta \mathrm{PD}$ : change in phylogenetic

663 dissimilarity; CCBF: index of cumulative change in biodiversity facets.

664 Tables S2 and S3 are also provided in a public online repository (figshare.com). Here is the 665 private link: https://figshare.com/s/5fadc2c14cbb1f39c25c. 